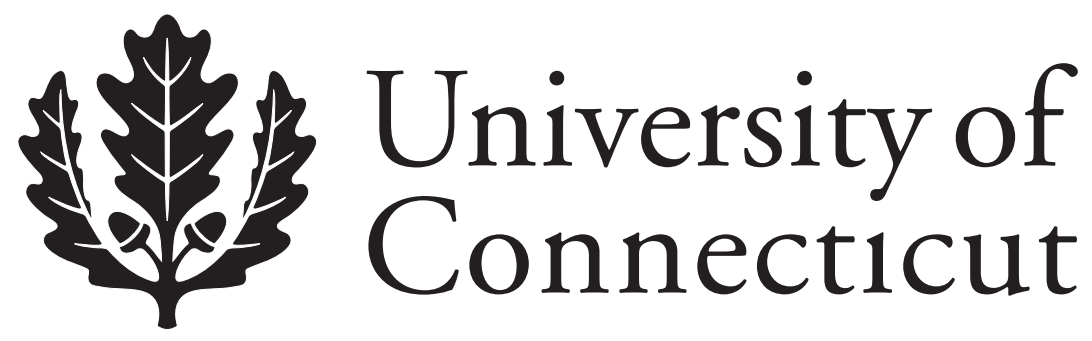

Department of Economics Working Paper Series

\title{
Measuring Unemployment Insurance Generosity
}

Stéphane Pallage

Université du Québec à Montréal

Lyle Scruggs

University of Connecticut

Christian Zimmermann

University of Connecticut

Working Paper 2008-42

November 2008

341 Mansfield Road, Unit 1063

Storrs, CT 06269-1063

Phone: (860) 486-3022

Fax: (860) 486-4463

http://www.econ.uconn.edu/

This working paper is indexed on RePEc, http://repec.org/ 


\begin{abstract}
In this paper, we develop a methodology to summarize the various policy parameters of an unemployment insurance scheme into a single generosity parameter. Unemployment insurance policies are multdimensional objects. They are typically defined by waiting periods, eligibility duration, benefit levels and asset tests when eligible, which makes intertemporal or international comparisons difficult. To make things worse, labor market conditions, such as the likelihood and duration of unemployment matter when assessing the generosity of different policies. We build a first model with such complex characteristics. Our model features heterogeneous agents that are liquidity constrained but can self-insure. We then build a second model that is similar, except that the unemployment insurance is simpler: it is deprived of waiting periods and agents are eligible forever with constant benefits. We then determine which level of benefits in this second model makes agents indifferent between both unemployment insurance policies. We apply this strategy to the unemployment insurance program of the United Kingdom and study how its generosity evolved over time.
\end{abstract}

Journal of Economic Literature Classification: J65, E24

Keywords: unemployment insurance, labor market policy, measurement 


\section{Introduction}

Because of their many dimensions, labor market policies are quite difficult to compare through time and space. Their generosity is not easily measured by any known aggregate statistic. Some programs can be restrictive in their access but very supportive of those admitted, while others are open to all, but distribute pennies. To make things worse, this generosity of labor market policies cannot be assessed independently from the economic environment in which they are applied at a given time. In a labor market with full employment, it does not really matter whether support for the jobless is very restrictive. It would, however, in a world in which unemployment is significant.

In this paper, we want to contribute to a better understanding of how generous, in an aggregate sense, some labor market policies are. We focus on unemployment insurance [UI]. Specifically, we want to study how the generosity of unemployment insurance has evolved in the United Kingdom by summarizing all dimensions of this policy into one policy parameter. This methodology can be used for other countries, thus ultimately also to compare different unemployment insurance systems across the world.

Quite obviously, we are not the first who try to compare UI systems. Notable recent predecessors are Martin (1996), Scruggs (2006) and Howell et al. (2007). Martin (2006) summarizes a series of results from an OECD research program that publishes international comparisons of UI coverages for various types of workers. Pointwise comparisons of the many dimensions of various social programs can be found in Scruggs (2006) for a specific type of household. Howell et al. (2007) try to gather labor market institution indicators and aggregate them into a few measures. These works, however, use little theory to discipline the indicators, as pointed out by Heckman (2007). Also, they ignore how local labor market conditions may matter. For example, whether the reduction of the eligibility period for UI benefits matters depends on local unemployment duration. Thus while duration of benefits is shorter in the United States than in most European countries, it may not imply that UI programs in the United States are less generous since the duration of unemployment is also shorter. US programs may even be more generous in dimensions that matter more for local labor market.

Our approach is one of model-based measurement. We simulate a dynamic general equilibrium model in which we confront two economies, one featuring the complete characteristics of an actual UI program (that of the United Kingdom), the other characterized by a one-dimensional UI program. This single dimension is the level of UI benefits with no time limit or eligibility criterion other than not 
having a job offer. The metric by which we measure the overall generosity of an unemployment insurance program is the level of benefits in the one-dimensional UI program that makes agents indifferent between that and the actual program. Our model is one of heterogeneous agents and stochastic employment opportunities in the spirit of Hansen and İmrohoroğlu (1992) and Pallage and Zimmermann (2001, 2005). Agents can self-insure through asset building but face liquidity constraints. There may be moral hazard in the sense that the UI agency may not always be capable of filtering all those who fraudulously apply for benefits. We consider this possibility in our sensitivity analyses.

With this methodology, our measurement captures the effect of possible changes in labor market conditions. It also accounts for the fact that agents' behavior will likely respond to changes in UI policies or changes in the labor market. Finally, our approach offers a unique way to identify the elements within the policy or the environment that affect most the UI generosity.

Besides the methodological contribution, our paper establishes an important empirical result: unlike commonly believed from a look at replacement rates or from previous measurement attempts (e.g. Scruggs, 2006), the actual generosity of the United Kingdom's UI system has declined substantially and in a sustained way since the 1980 s.

In the next sections, we present the modeling strategy. We then calibrate our model to the economy of the United Kingdom, paying special attention to the households, the labor market and the UI policies. We perform simulations and present their results in Section 4. We conclude in Section 5.

\section{Modeling strategy}

We build two models, comparable in every element but one, the UI policy in place. In the first model, there is a detailed unemployment insurance program, with a vector of characteristics, replacement ratio, eligibility requirements, duration of benefits, etc, that match those in place in the United Kingdom. In the second model, the unemployment insurance is the simplest possible, specifying a replacement ratio that is accessible to the jobless as long as they remain so, without any further eligibility clauses. For exposition purposes, we want to start by describing the common parts, i.e., the household problem. 


\subsection{The household problem}

We work within an economy with random job opportunities and indivisible labor. Households care about consumption and leisure, which they choose optimally to maximize an infinite stream of expected, discounted utilities. Savings can be used to self-insure against adverse employment shocks, but there is no borrowing possibility. Every period, households enter an employment opportunity lottery. The likelihood for households to be given a job offer depends on whether they had such an offer the period before. In any case, households may choose to accept or turn down a job opportunity. A publicly financed unemployment insurance program provides some income replacement benefits to the unemployed under some conditions. The UI agency operates with a balanced budget rule. Its revenues are collected from income taxes.

The preferences of a typical household can be represented by the following function

$$
\max E_{0} \sum_{t=1}^{\infty} \beta^{t} u\left(c_{t}, l_{t}\right)
$$

where $u(\cdot)$ is a utility function with the usual properties, i.e. increasing in each argument and concave; $c$ stands for consumption, $l$ for leisure: $l_{t}=1$ for someone who does not work, $l_{t}=1-\hat{h}$ for someone who works an indivisible amount of time $\hat{h} ; \beta \in[0,1)$ is the discount factor.

Savings $m$ from a period to the next evolve in the following way:

$$
m_{t+1}=m_{t}+y_{t}^{d}-c_{t}, \quad m_{t} \geq 0 \quad \forall t
$$

where $y_{t}^{d}$, the disposable income can have one of three possible values:

$$
y_{t}^{d}= \begin{cases}(1-\tau) y & \text { if employed }(w=e) \\ (1-\tau) \theta y & \text { if eligible to UI }(w=i) \\ (1-\tau) \psi y & \text { if unemployed and not eligible }(w=u)\end{cases}
$$

where $\tau$ is the income tax rate used to raise the necessary revenue to finance the unemployment insurance program and $w$ is an indicator of UI labor market status. There may be various indicators of eligibility for unemployment insurance benefits. $\theta$ and $\psi$ represent income replacement rates. We will call $\alpha$ the vector of UI parameters that will be specified for each model below. Besides replacement rates, $\alpha$ may also contain eligibility parameters such as waiting period, benefit duration, asset tests, etc. For the time being, we will say that eligibility depends on 
a vector of variables $s_{t}$ that changes according to some, potentially endogenous, law of motion / chi:

$$
s_{t+1}=\chi\left(s_{t}\right)
$$

The labor market is stochastic in the following sense. Job opportunities are drawn from a lottery, following a simple binomial Markov process. The probability to be given a job offer at time $t$ depends on whether such offer was given at $t-1$.

To sum up the household problem, we can write it down in recursive form, using a Bellman equation. For an agent with an employment offer, the relevant Bellman equation is:

$$
\begin{aligned}
& V(m, s, e ; \alpha)=\max \left\{\begin{array}{l}
\max _{m^{\prime}} u(c, 1-\hat{h})+\beta \int_{s^{\prime} \mid e} V\left(m^{\prime}, s^{\prime} ; \alpha\right) d\left(s^{\prime} \mid e\right), \\
\max _{m^{\prime}} u(c, 1)+\beta \int_{s^{\prime} \mid u} V\left(m^{\prime}, s^{\prime} ; \alpha\right) d\left(s^{\prime} \mid u\right)
\end{array}\right\} \\
& \text { S.T. } \quad m^{\prime}=m+y^{d}(e ; \alpha)-c \\
& m^{\prime} \geq 0 \\
& s^{\prime}=\chi(s)
\end{aligned}
$$

It should be emphasized that when an agent turns down a job offer, he jumps straight to state $u$ (ineligible for UI).

In a similar fashion, the Bellman equation for an agent without a job offer can be written as:

$$
\begin{aligned}
V(m, u, s ; \alpha)= & \max _{m^{\prime}} u(c, 1)+\beta \int_{s^{\prime} \mid u} V\left(m^{\prime}, s^{\prime} ; \alpha\right) d\left(s^{\prime} \mid u\right) \\
& m^{\prime}=m+y^{d}(x ; \alpha)-c \quad x=i \text { or } u \\
& m^{\prime} \geq 0 \\
& s^{\prime}=\chi(s)
\end{aligned}
$$

where the difference between UI eligible $(x=i)$ and ineligible $(x=u)$ is driven by the law of motion of $s$ and yields different disposable incomes.

\subsection{Equilibrium}

In this model, a steady-state equilibrium is an allocation of work, asset and consumption for all agents, a value function $v(\cdot)$, a distribution of assets $f(\cdot)$, and a tax rate $\tau$ such that: 
1. agents solve their individual intertemporal problems, given $(\alpha, \tau)$ and labor market characteristics;

2. the unemployment insurance agency balances its budget;

3. there is an invariant distribution of agents.

Under this definition of equilibrium, agents assume that the current unemployment insurance and labor market characteristics in any given period will remain unchanged forever. One may question this myopic view of the world. An alternative would be to take into account how agents are forward looking in these dimensions as well, that is, how they look forward to changes in the parameters of the UI system and how the unemployment rate and duration change. Modeling these expectations, however, is non-trivial. It would make the computation of equilibrium several degrees more difficult, as it would no longer be possible to rely on invariant distributions. We chose the easier path. We do not expect, however, that such policy changes would matter much in terms of expectations, as long as they are not large and are not announced long in advance.

\subsection{The simplified UI program}

We need to specify the rules that govern the simple UI program, its generosity and eligibility criteria, i.e. $\alpha$. For this simplified UI program, we assume that unemployment benefits can be obtained immediately and that unemployed households stay eligible as long as they remain without a job offer. If eligible, they receive every period the same proportion $\theta$ of their income. An agent is ineligible as soon as she turns down a job offer. In that case, she receives a fraction $\psi$ of past income.

The simplified UI program thus has the following vector of parameters to which we want to map the detailed UI program:

$$
\alpha=(\theta, \psi) .
$$

\subsection{The detailed UI program}

Next, we want to describe the rules of a real world unemployment insurance policy in as many details as computationally feasible. Such policy typically has the following components: 
1. A waiting period $a$, before the end of which unemployed agents are not eligible for full benefits, although there may be partial benefits in the meantime.

2. The duration of eligibility $z$, i.e., the number of periods an unemployed agent is entitled to receive benefits.

3. The proportion of income that unemployed agents obtain as benefits, $\theta(j)$, which may vary through the unemployment spell, including the waiting pe$\operatorname{riod}(j=1, \ldots, z)$.

4. The proportion of income unemployed agents may receive after losing eligibility, $\psi$, for example through other social programs.

The vector of policy parameters we need to calibrate from the data is therefore given by:

$$
\alpha=\left(a, z,\{\theta(j)\}_{j=1, \ldots, z}, \psi\right) .
$$

We can now turn to finding those policy parameters for the economy of interest.

\section{Parametrization to the United Kingdom}

In this first exercise, we want to see how the generosity of the UI program, as summarized by $\theta$ in the simplified setup, may change through time. For this purpose, we use the characteristics of $\alpha$ for the United Kingdom for every year, along with the relevant labor market data to parametrize the job-opportunity lottery.

The UK unemployment benefit system is summarized in Figures 1 and 2. It was subject to major changes in the early 1980s. ${ }^{1}$ From 1966 to 1981, the UK unemployment insurance system consisted of two tiers - a flat rate benefit and an earnings-related benefit. Since 1982, the system consists of a single flat-rate benefit, as it did before 1966.

Throughout the period examined in this paper (1972-2002), the flat rate benefit, referred to as the "immediate benefit" in Figure 1, was payable after a waiting period of three days, for up to 52 weeks. While it was in force through 1981, the

\footnotetext{
${ }^{1}$ A useful summary of the benefit conditions prior to the early 1980 s is Atkinson and Micklewright (1985) Chapter 2.
} 
earnings-related benefit was payable, on top of the flat rate benefit, for up to 26 weeks and after a 12-day (two-week) waiting period. "UI benefits" in Figure 1 refers to the combined flat-rate and earnings-related replacement rates for 19721981. The "income support" replacement rate in Figure 1 refers to means-tested, social assistance benefits which have existed under several different names over the years. The means test changed over time as well and is shown as "asset test."

All of the parameters in Figures 1 and 2 are based on the actual policies in force for the years in question. All figures except for social assistance benefit replacement rates were taken from the summary data set of the Comparative Welfare State Entitlement Data set (see Scruggs, 2005). Benefit replacement rates were computed assuming a single-person household with net, in-work wages equal to the average production worker (APW) in the year in which benefits were computed. Benefit rates were based on those in place on April 15 of the year in question. Benefit replacement rates assume a six month unemployment spell, with the six-month total benefit annualized and divided by the net annual wage of the APW. (Annualization facilitates the computation of income tax burdens.) Social assistance replacement rates are taken from the United Kingdom's Department of Work and Pensions as reported in the Institute for Fiscal Studies (2006). Weekly assistance rates (which are not taxable) were simply multiplied by 52 and divided by the net APW wage. The asset test is based on the maximum allowable assets divided by disposable APW.

The reform of 1982 did not just change the various benefits. Their tax treatment also changed. Specifically, UI benefits became taxable in 1983, while income support has never been taxable. As seen in Figure 1, taking into account the tax treatment of benefits leads to the odd situation after the reform that UI benefits were lower than income support. However, UI benefits are not means tested, while income support is. Note that for this analysis, we used the effective labor income tax rates published by Mendoza, Razin and Tesar (1994), where we complement the published numbers until 1996 with the update available on Enrique Mendoza's web page. After 1996, we assume no change in the tax rate. One can reasonably argue that these tax rates are too high for our exercise: they are defined as economy-wide average rates, and unemployed workers most likely pay lower tax rates as their income is lower when unemployed and their base income is lower than average. Thus we want to take the parametrizations with and without tax considerations as upper and lower bounds in our measure of UI generosity. ${ }^{2}$

\footnotetext{
${ }^{2}$ Note that due to the endogenous response in self-insurance, tax benefits may lower our measure of generosity in some circumstances.
} 
To calibrate the job market lottery in our model, we make use of the fact that in a binomial Markov process, the probability of receiving a job offer while unemployed is the inverse of the unemployment duration. Furthermore, together with the probability of getting a job offer while employed, it determines the unemployment rate Thus, we use time series for the unemployment rate and unemployment duration to parametrize the odds of the lottery in each year. While the unemployment rate is easily available from the United Kingdom's Office of National Statistics, duration data is another matter. We use data on inflows and outflows of UI claimants, again from the ONS, but available only starting in 1989. For the earlier years, we use the numbers published by Layard, Nickell and Jackman (1991, p. 224). Clearly, we would prefer having durations for all unemployed workers. However, using the unemployment rate along with claimant flows gives us durations that should not lie too far from the truth. Atkinson and Micklewright (1985) present evidence for the period 1972-1977 that there is no significant bias, with unemployment duration averaging at 33.4 weeks, while claimant duration is 31.7 weeks. The unemployment rate and duration are presented in Figure 3.

The remaining parameters and functional forms are standard to the literature. Following Hansen and İmrohoroğlu (1992) and the literature that followed, we let the utility function be

$$
u(c, l)=\frac{\left(c^{1-\sigma} l^{\sigma}\right)^{1-\gamma}}{1-\gamma}-1
$$

with $\sigma=0.67$ and $\gamma=2.5$. Leisure $l$ is one when unemployed and 0.55 when working. Also, we set the discount factor $\beta$ such that it corresponds to a discount rate of $4 \%$ per year. When running the simulations, we consider the time frequency to be weekly. Such a high frequency is necessary to capture key features of the United Kingdom's UI policy. The eligibility waiting period is one week for part of our sample.

\section{Results}

Our solution algorithm is as follows. We first solve numerically the model with the detailed UI program for each year in the sample. This is performed by transforming the state space, in particular assets $m$, into a grid, then using discrete dynamic programming techniques to obtain a solution through iterations on the value function. Given the resulting value function and invariant distribution of agent types, we can obtain the expected value of a UI program, call it $W$. 
The next step implies solving the model with the simplified UI program using the same technique. We search through various values of $\theta$ until we find the one that provides the expected value closest to $W$. This is done for every year in our 1972-2002 sample, thereby giving us the path of UI generosity over time.

Note that the value function of the simplified economy in non-monotonic in $\theta$. Indeed, with $\theta=0$, individuals must bear their employment risk completely and need to self-insure through asset accumulation, which is costly. With $\theta=1$, income in completely insured, but because agents also value leisure they would actually prefer a lower $\theta$, as $\theta=1$ implies that being unemployed is better than being employed. Also, high $\theta$ implies higher taxes. Therefore, there is an optimal $\theta$ somewhere in between, and it is unlikely that this optimal $\theta$ corresponds to the one we find in the simulation. This means that for any value $W$ we try to match, there are two corresponding $\theta$, as for tax rates in a Laffer curve. In our simulations, one of those two replacement rates always has an unreasonable value (above $100 \% \ldots)^{3}$ We pick the reasonable one.

Note that it is theoretically possible for the complex economy to attain a value that is unreachable by the simple one. For example, if the complex economy has features like those described in Shavell and Weiss (1979) or Hopenhayn and Nicollini (1997), where benefits are optimized as they vary over the unemployment spell or thereafter. While in our experience so far it has not been a problem, it could be one in more generous UI systems than the one studied here.

Our simulated $\theta$ is presented in Figure 4. The figure shows that unemployment insurance became dramatically less generous in the early 1980's and this trend has continued since. Such a results is not self-evident from the parametrization. While indeed progam benefits declined in a similar fashion, the waiting period was reduced and the eligibility to UI was lengthened. It turns out the latter is inconsequential in conjunction with the changes in the labor market. We also notice that our simulated benefits are most of the time significantly below the program UI benefits. The restrictions to eligibility thus have a significant impact. Finally, simulated benefits are much more variable, reflecting the changing labor market conditions as well as the other program parameters. Also, early in the sample, some of the variability is due to the fact that generosity was closer to a social optimum, and thus was in a flatter portion of the average value function.

These various influences can be disentangled, but let us first have a look at an alternative measure of generosity. A "naive" and much simpler way to proceed

\footnotetext{
${ }^{3}$ Note that a negative value may not be inconceivable for low UI benefits and tight asset tests for various benefits, due to the endogenous response in asset accumulation.
} 
would be to compute the present value of benefits under the current system and compute the corresponding "permanent income," $\theta$ :

$$
\sum_{t=1}^{a} \beta^{t-1} \theta_{t}+\sum_{t=a+1}^{a+z} \beta^{t-1} \theta_{t}+\sum_{t=a+z+1}^{\infty} \beta^{t-1} \psi=\frac{1}{1-\beta} \theta .
$$

Now compare this naive $\theta$ to the simulated $\theta$ we obtained before in Figure 5. While the naive $\theta$ would have recognized a decline in UI generosity, it would have in no way registered the huge decrease in the early eighties. Several factors contribute to this mismeasurement: The naive measure does not take into account changes in the labor market, ignores means tests, and it does not factor in how workers' behavior changed in terms of self-insurance. In particular, the naive measure displays even less of a decline than the program UI benefits.

What influences our generosity measure? There are two ways to determine this: by regressing it on its determinants, and by performing counterfactual analyses. Table 1 displays the results of the regression. Obviously, this exercise is full of flaws, starting with the small sample and correlated explanatory variables. But the fact that the interval on the coefficients is very large highlights that the relationships may not be linear. Also, some variables could have a large impact. The last column describes the change in generosity resulting from the smallest to the largest value in the sample. We see that quite expectedly UI benefits have a strong impact, but so do wait times, the unemployment rate and unemployment duration, and to a lesser extend the other program variables.

We believe, however, that the proper way to evaluate the impact of the program variables and the labor market conditions is through counterfactuals using our model. The idea here is to run the same simulations as before, but with modified variables. In Figures 6 to 13, we look in turn at each variable, whereby the variable is set at its average value in the sample. Thus, any difference with the benchmark simulation is due to variations in the variable at hand, variations that incorporate the endogenous responses of the model households.

Take Figure 6. Here, the unemployment rate is set for the whole sample period to its average value of $7.46 \%$. While the unemployment rate does not seem to affect the general downward trend of generosity, it seems to affect some of its variablity, in particular in the latter sample period. The reverse is true for UI benefits: they clearly explain the trend in generosity, but not variability (Figure 7).

Looking further at other variables, unemployment duration affects somewhat the variability of generosity (Figure 8 ), and wait times have virtually no impact 
(Figure 9). Figure 10 shows benefit duration during the last seven years lasting as long as before the reform, i.e. 52 instead of 26 weeks. Generosity increases, but relatively little. Changes in incomes security affect outcomes about as much as several of the other variables did (Figure 11). The impact of tax benefits for unemployed workers is more substantial, see Figure 12. Interestingly, for recent years, removing tax benefits improves generosity through the endogenous response of households who self-insure more and thus rely less on unemployment insurance. Finally, we see on Figure 13 that the introduction of asset tests that were truly binding has had a substantial impact, in particular during the early eighties when benefits were more generous than today.

All in all, these counterfactual experiments show that, except for the wait period, all changes in labor market conditions and program parameters have a measurable impact on program generosity. It is therefore important to take them all into account for any evaluation of the generosity of an unemployment insurance system.

Other parameter values that are not related to the unemployment insurance program or the labor market conditions, such as risk aversion or the discount rate, may also influence our measure of generosity. However, as a modification of such a parameter value would affect both the complex and the simple model economies, the impact is moderate. The strongest impact comes from a change in the risk aversion parameter, as shown in Figure 14.

Moral hazard may also have an impact, as workers may choose to shirk differently, depending on the generosity of the system. But as the generosity would be comparable, by definition, in the complex and simple model economies, this should only have a negligible impact, unless there are some very strong amplification mechanisms in play with asset accumulation. When amending the model with the possibility of moral hazard much in the same way as Hansen and Imrohoroğlu (1992) and Pallage and Zimmermann (2001), we find that workers do not bother to shirk as the UI system is not sufficiently generous in the case of the UK.

\section{Conclusion}

We view the main contribution of this paper as methodological. We develop a method to determine a comparable one-dimensional measure the level of generosity of a social program, in our case the unemployment insurance, based on a micro-founded model. Specifically, we draw a model where heterogeneous agents face labor market shocks, react by accumulating assets and use a multi- 
dimensional UI system. We then determine how generous a one-dimensional UI system needs to be for agents to be indifferent between the two.

Our second contribution is empirical. Parametrizing our model economies to the period 1972-2002 in the United Kingdom, we find dramatic drops in the generosity in the early 1980's despite more generous UI eligibility. Since then, generosity of unemployment insurance in the UK has continued to decline. We show that the severity of this drop would not have been captured by a measure of generosity that would have focused solely on the parameters of the system, thereby ignoring the changing labor market and the reactions of the agents.

The methodology we have presented here can be applied in many ways. For example, it makes international comparisons of unemployment insurance or other social programs possible.

\section{References}

Atkinson, A. B. and Micklewright, John, 1985. "Unemployment Benefits and Unemployment Duration: A Study of Men in the United Kingdom in the 1970s," London: Suntory-Toyota International Center for Economics and Related Disciplines.

Hansen, Gary D. and İmrohoroğlu, Ayse, 1992. “The Role of Unemployment Insurance in an Economy with Liquidity Constraints and Moral Hazard," Journal of Political Economy, University of Chicago Press, vol. 100(1), pages 118-42, February.

Heckman, James, 2007. " Comments on Are Protective Labor Market Institutions at the Root of Unemployment? A Critical Review of the Evidence by David Howell, Dean Baker, Andrew Glyn, and John Schmitt," Capitalism and Society, bePress, vol. 2(1), article 5 .

Hopenhayn, Hugo A and Nicolini, Juan Pablo, 1997. "Optimal Unemployment Insurance," Journal of Political Economy, University of Chicago Press, vol. 105(2), pages 412-438, April.

Howell, David R., Baker, Dean, Glyn, Andrew and Schmitt, John, 2007. "Are Protective Labor Market Institutions at the Root of Unemployment? A Critical Review of the Evidence," Capitalism and Society, bePress, vol. 2(1), article 1.

Institute for Fiscal Studies, 2006. "Fiscal Facts: Benefit Tables for Income Support and Supplementary Benefits." Updated March 2006. http://www.ifs.org.uk/ff/ indexben.php (Accessed June 10, 2007) 
Layard, Richard, Nickel, Stephen, and Jackman, Richard, 1991. "Unemployment: Macroeconomic Performance and the Labour Market," Oxford University Press.

Martin, John P., 1996. "Measures of Replacement Rates for the Purpose of International Comparisons: A Note," OECD Economic Studies, OECD, number 26, pages 99-115.

Mendoza, Enrique, Razin, Assaf and Tesar, Linda, "Effective tax rates in macroeconomics: Cross-country estimates of tax rates on factor incomes and consumption," Journal of Monetary Economics, vol. 34(3), pages 297-323, December.

Pallage, Stéphane and Zimmermann, Christian, 2001. "Voting on Unemployment Insurance," International Economic Review, vol. 42(4), pages 903-23, November.

Pallage, Stéphane and Zimmermann, Christian, 2005. “. Heterogeneous Labor Markets and the Generosity Towards the Unemployed: An International Perspective." Journal of Comparative Economics, 33(1), pages 88-106, March 2005.

Scruggs, Lyle, 2005. "Welfare State Entitlements Data Set: A Comparative Institutional Analysis of Eighteen Welfare States," Version 1.0b, http://sp.uconn.edu/ $\sim$ scruggs/wp.htm (Accessed June 10, 2007)

Scruggs, Lyle, 2006. "The Generosity of Social Insurance, 1971-2002," Oxford Review of Economic Policy, Oxford University Press, vol. 22(3), pages 349-364, Autumn.

Shavell, Steven and Weiss, Laurence, 1979. "The Optimal Payment of Unemployment Insurance Benefits over Time," Journal of Political Economy, University of Chicago Press, vol. 87(6), pages 1347-1362, December. 
Table 1: Regression of simulated $\theta$ on parameters

\begin{tabular}{|l||r|rr|r|}
\hline Parameter & coefficient & \multicolumn{2}{|c|}{$95 \%$ interval } & impact on $\theta$ \\
\hline \hline Constant & 0.370 & -0.104 & 0.844 & 0.000 \\
Immediate benefit & -0.475 & -3.295 & 2.345 & -0.070 \\
UI benefit & 2.624 & 0.668 & 4.580 & 0.842 \\
Income support & -0.628 & -2.716 & 1.459 & -0.072 \\
Asset test & 0.058 & -0.091 & 0.208 & 0.051 \\
Wait time & -0.243 & -0.472 & -0.013 & -0.364 \\
UI duration & -0.002 & -0.006 & 0.001 & -0.058 \\
Unemployment rate & -2.023 & -5.880 & 1.834 & -0.164 \\
Unemployment duration & 0.010 & -0.001 & -0.021 & 0.326 \\
Tax & -1.307 & -3.713 & 1.099 & -0.073 \\
\hline
\end{tabular}

Figure 1:

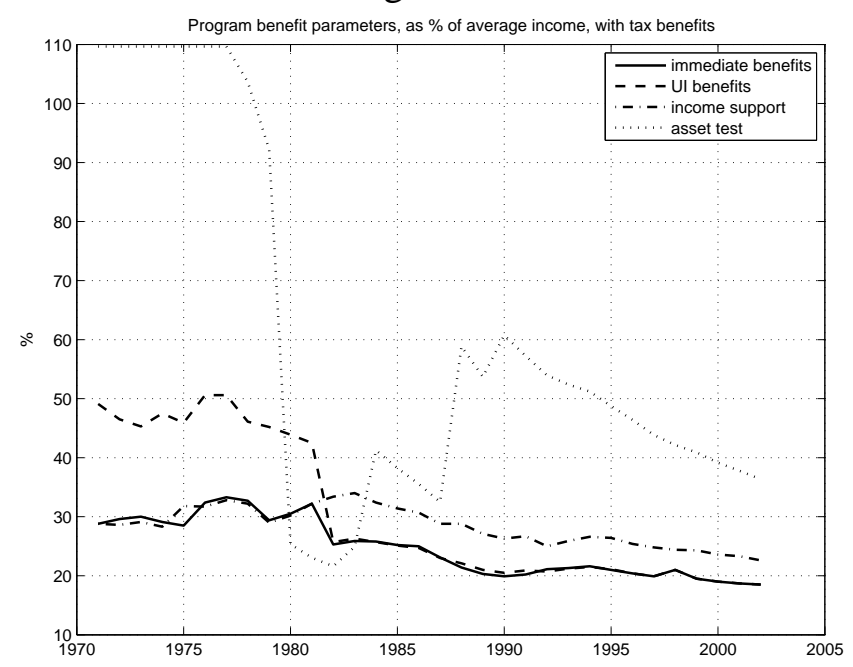


Figure 2:

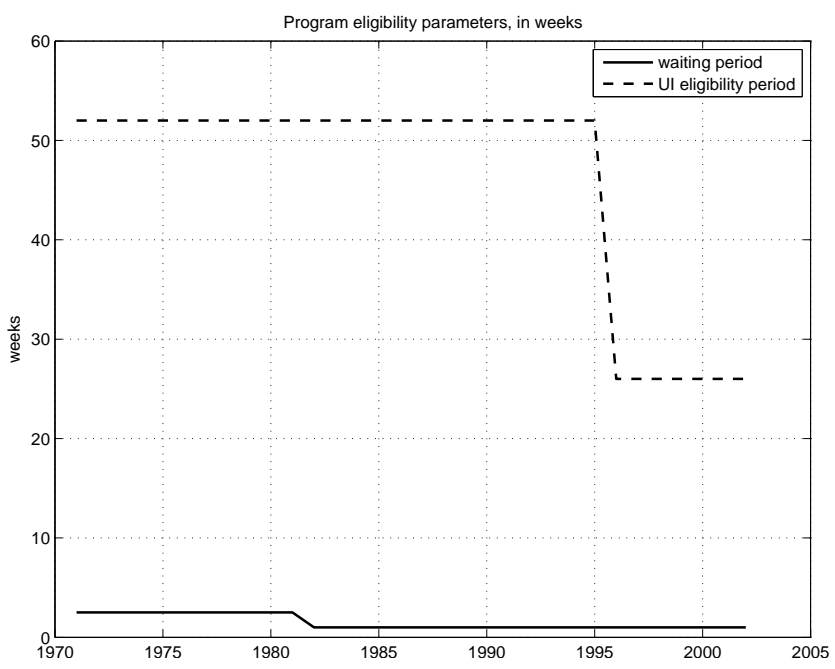

Figure 3:

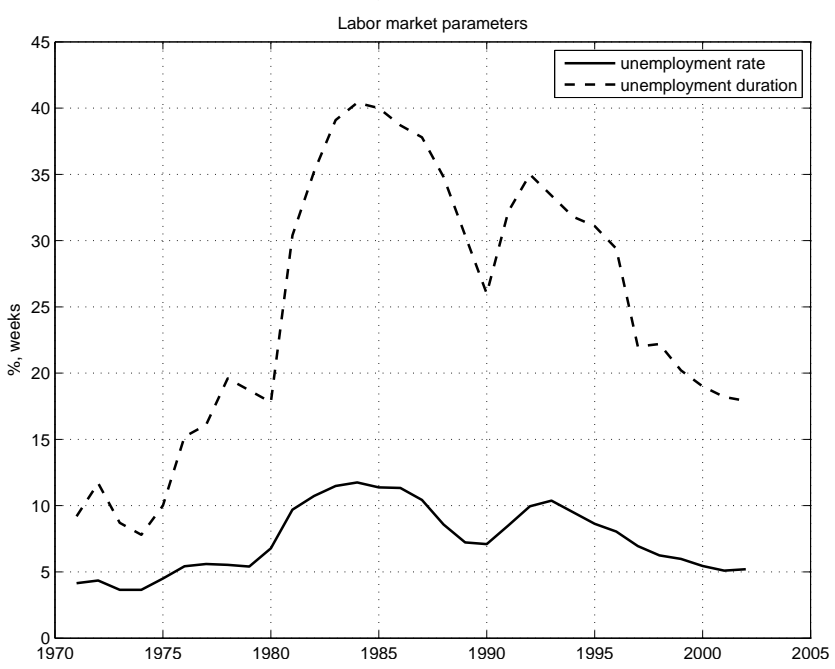


Figure 4:

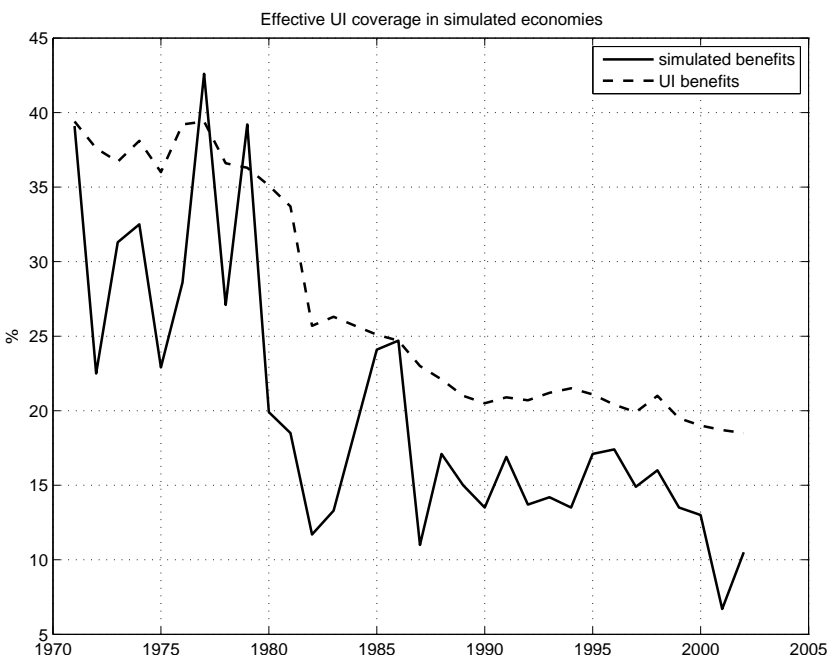

Figure 5:

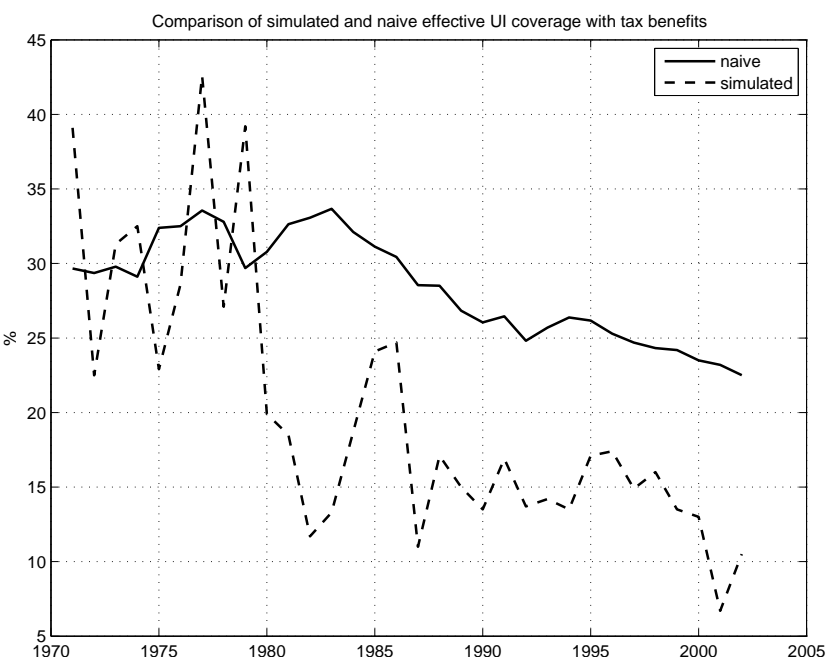


Figure 6:

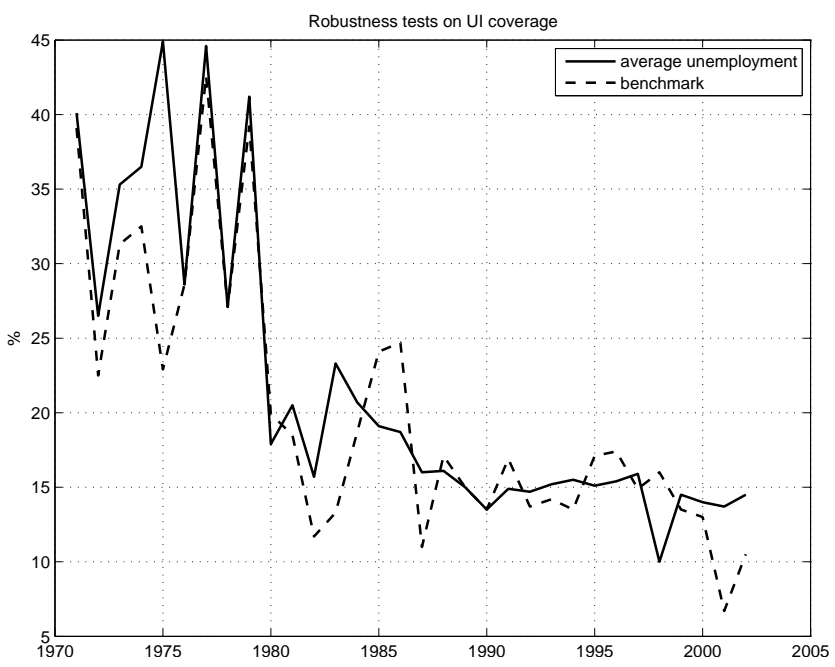

Figure 7:

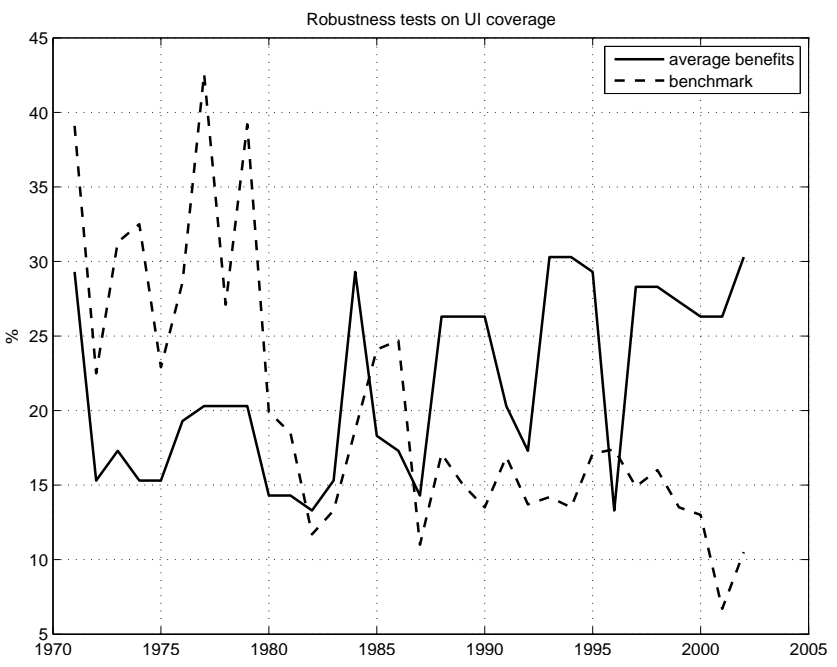


Figure 8:

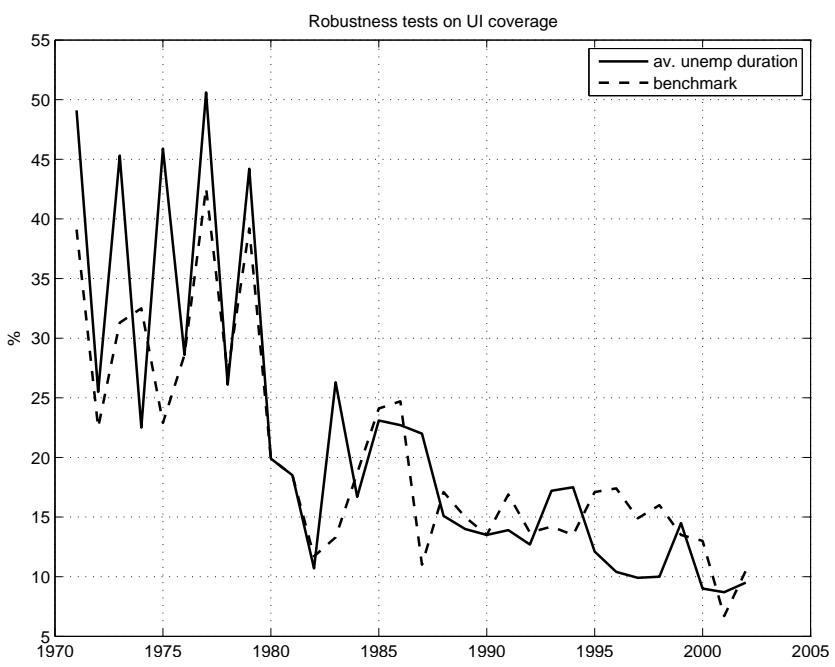

Figure 9:

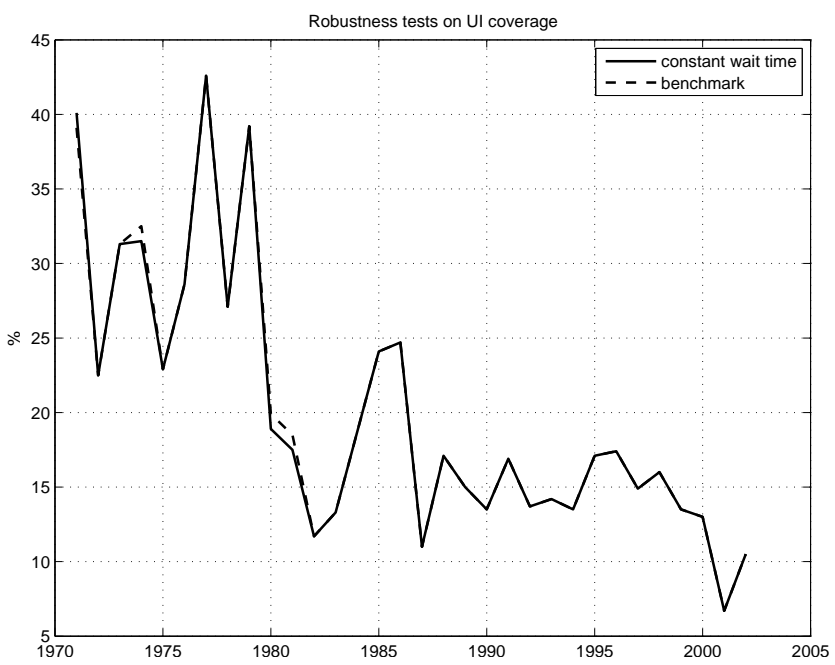


Figure 10:

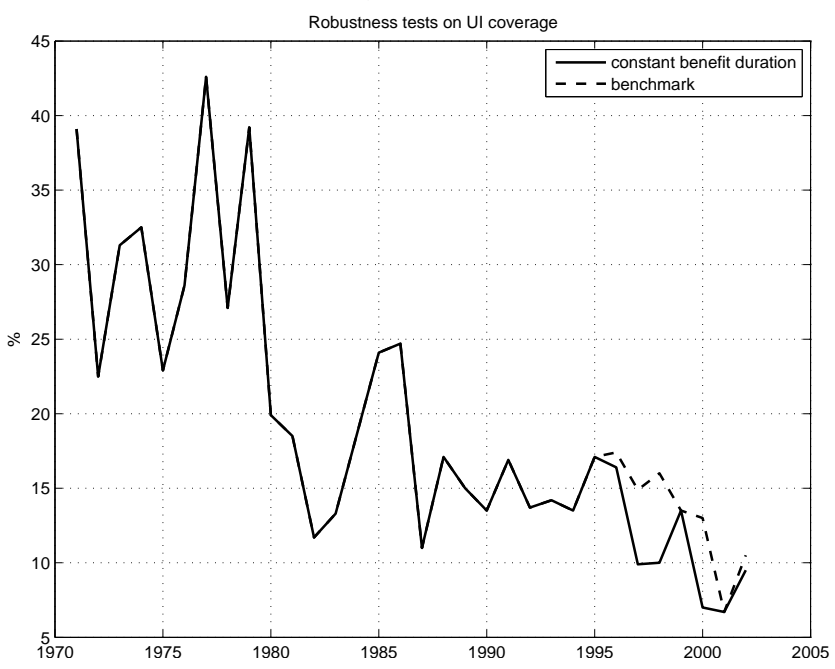

Figure 11:

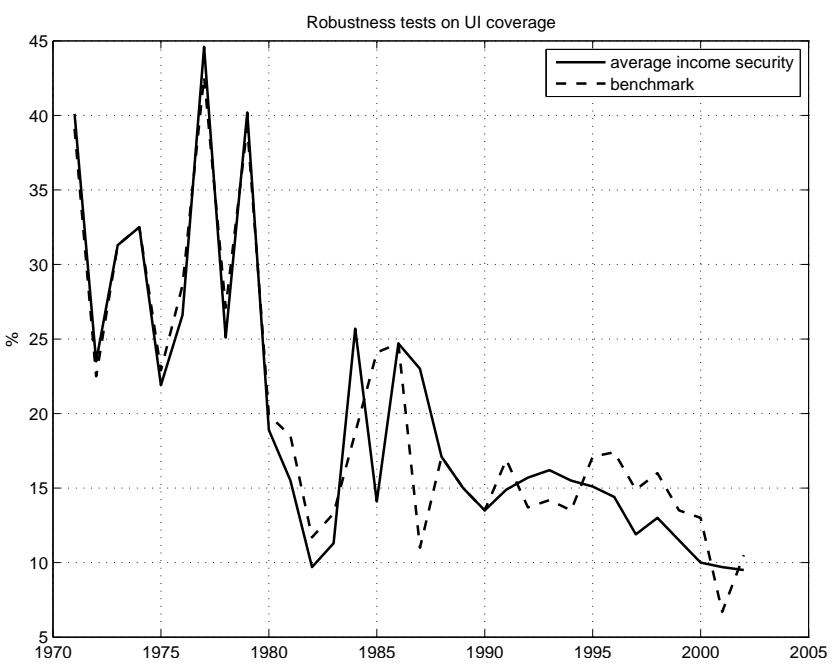


Figure 12:

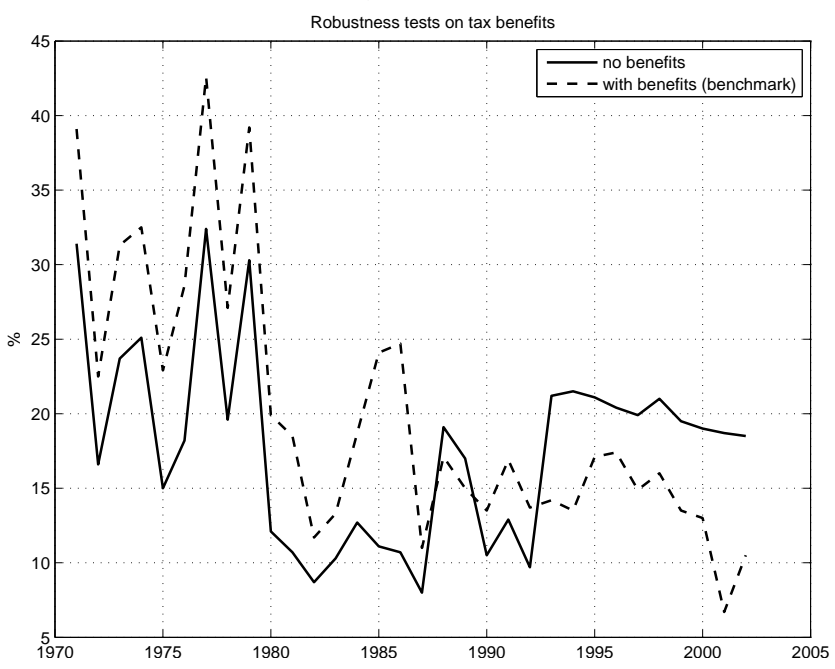

Figure 13:

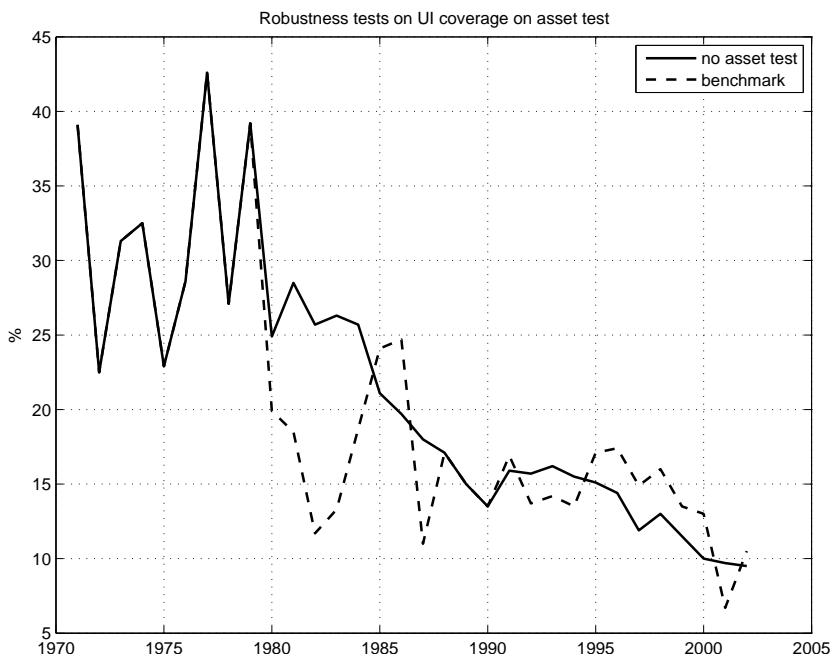


Figure 14:

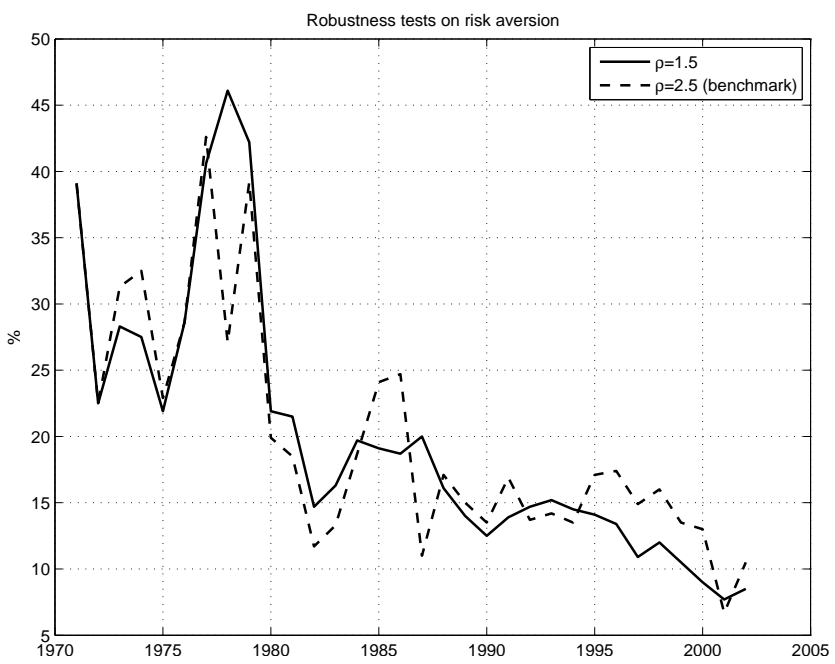

